single curves, is only the commencement of the subject, since the next step will consist in co-ordinating the analyses of curves from several places; this would greatly enhance the usefulness of this method of forecasting.

The author does not, however, appear to lay enough stress on the fact that forecasting pressure is by no means equivalent to forecasting weather, and that the correlation between rainfall and the height of the barometer at a place, or even the connexion between rainfall and pressure distribution over an area, is none too close from a forecaster's point of view. One has also to consider the tendency of the weather to get into dry or wet " grooves "; for it is well known that during pronouncedly wet spells, downpours occur in passing barometric configurations that would scarcely yield a drop during a dry spell. Moreover, it does not follow that Vercelli's method, even if found practicable in Italy, would answer in England, where it is possible that the relationship between pressure and weather may be rather more complex. It is just such climatic peculiarities we want to discover, and it is not too much to say that even if a universal application of Vercelli's system to weather forecasting proved wholly unserviceable, which is scarcely likely, it could not fail to bring to light any such interesting climatological differences between one region and another.

L. C. W. Bonacina.

\section{Wind, Wave, and Swell on the North Atlantic Ocean. ${ }^{1}$}

DURING a voyage from Southampton to Trinidad and back by R.M.S. Oruba the period of the waves was taken several times daily, and from this their speed was calculated. The speed of the wind was ascertained by means of a Robinson anemometer (lent by the Meteorological Office), due allowance being made for the speed of the ship and the direction of the wind.

The water is very deep from a short distance beyond Ushant, and free from strong currents so far as Barbados. The speed of the wind ranged from 13.9 to 23.6 statute miles per hour. That of the waves was in all cases less, the difference ranging from I.o mile an hour to a little more than 8.0 miles an hour. The latter is sufficient to keep a light flag flying. Anything less than I mile an hour is reckoned a calm. The difference was not proportional to the speed of the wind; nevertheless a relationship emerges when account is taken of the observations which were made simultaneously of the swell of the sea. When swell and wave ran precisely in the same direction (as sometimes occurred in the region of the Trade winds) and on one day when no swell was recorded, the speed of the wave was so nearly equal to that of the wind that the breeze blowing over the ridges was only equal to the "light air " which barely suffices to give steerage way to a fishing smack. Such a light air would be detected on land by drift of smoke but would not move a wind-vane. Thus there was no longer a battle between wind and wave.

When the swell followed but crossed the wave the difference in speed of wind and wave was greater, and this difference increased rapidly when the crossing swelling swell was meeting, instead of following, the wave. When the waves were much slower than the wind their height was always small, and sometimes their fronts were short and irregular. It was evident that the growth of waves in both length and height

1 Substance of a paper by Dr. Vaughan Cornish read before Section E (Geography) of the British Association at Toronto on August 8. was much hindered by a crossing swell, and it can be safely inferred that the general absence of swell is a sufficient reason for the rapid rise of waves upon enclosed seas. When a wind comes on to blow in the direction of the ocean swell with a speed greater than that of the swell, the growth of large, steep waves is very rapid (doubtless even more rapid than their growth from smooth water), but this occurrence is relatively rare in the North Atlantic.

The direction of the breaker out at sea was found to be intermediate between that of wave and swell (the breaker being formed when they override), so that the practice of observing the direction of "the curl on the water " as a method of determining the direction of the wind gives an erroneous result whenever there is a crossing swell, which is the usual condition upon the oceans. The general run of the waves, on the contrary, gives a trustworthy indication of the direction of the wind.

\section{Mountain Structure.}

THE origin of mountains continues one of the most controverted problems in geology, because geological maps of mountain areas are most difficult to prepare, and the interpretation of mountain structure involves appeal to layers of the crust far too deep for direct observation. The American Geological Society has arranged a symposium of nine papers on the development of mountains, ${ }^{1}$ which is the best available summary of modern opinion on the subject and illustrates its diversity.

The series opens by a masterly sketch by Prof. Schuchert of the development of research on orogeny from its foundation by $H$. $H$. Rogers, and of the evolution of North America, illustrated by I7 maps. He compares the American school with Haug's view of geosynclinals, which he rejects as untenable. Amongst several useful new terms proposed is "tafrogenesis" for rift valley formation.

Mr. Longwell's paper on Kober's theory is appropriate, as it deals with an extension of the subsiding belt explanation of mountain formation. Kober reclassifies the Alpine elements to avoid that asymmetry in mountain chains which Suess emphasised as their distinctive feature. Prof. Hobbs rejects Suess's arrangement of the Asiatic arcs, and assigns many of them to a direction of movement opposite to that adopted by Suess.

The structure of Appalachia naturally plays a large part in the symposium, and is discussed by J. B. Woodworth and Arthur Keith, whose conclusions are opposite. The former adopts isostasy, which Keith criticises adversely. He attributes the Appalachians to the intrusions of many granitic 'batholiths; in a valuable discussion of rival theories he rejects the shrinkage of the earth, owing to the astronomical disallowance of the necessary reduction in size; but if the geological evidence for the contracting earth is adequate the astronomers will doubtless find some reconciliation of that fact and their calculations.

The structure and building of the Rocky Mountains is discussed by G. R. Mansfield and W. T. Lee, whose paper is accompanied by appendices by C. E. Van Ostrand and W. D. Lambert. Mansfield rejects Kober's view that rift valleys are accompanied by compression, and insists that they are due to tension. Lee describes the Southern Rocky Mountains as due to vertical uplift in the restoration of isostatic equilibrium.

1 Symposium on the Structure and History of Mountains and the Causes of their Development. Bull. Geol. Soc. Amer., Vol, 34, Pt. 2, June 30, r923, pp. I5 I-380, I pl

No. 2863 , VOL. I I 4 ] 